Оригинальная статья/Original article

УДК 338.2

DOI: http://doi.org/10.20914/2310-1202-2018-2-490-496

\begin{tabular}{c}
\hline \hline Организационно-экономические особенности функционирования \\
малых предприятий лесного сектора экономики и причины \\
усиления деформации предпринимательской деятельности \\
\hline \hline
\end{tabular}

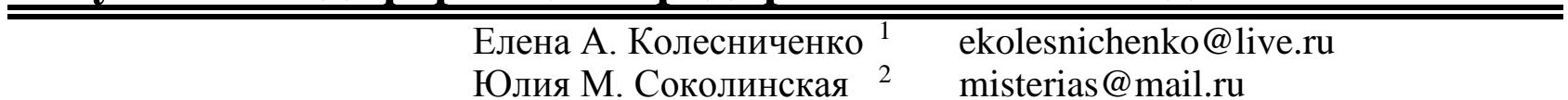

$\overline{\mathbf{1}}$ Тамбовский государственный университет имени Г.Р. Державина, ул. Интернациональная, 33, Тамбов, 392000, Россия

${ }^{2}$ Воронежский государственный университет инженерных технологий, пр-т Революции, 19, г. Воронеж, 394036, Россия

Реферат. В современных российских условиях хозяйствования приобретает важность анализ деформаций в развитии малого предпринимательства в тех секторах экономики, которые имеют стратегически важное значение для развития экономики всей страны. Так, для России стратегическими ресурсами, определяющими вектор развития ее экономики, среди прочих выступают лесные. Это связано с тем, что Россия является самой крупной в мире страной, обладающей лесными ресурсами. Она занимает первое место в мире по площади лесов и объему запасов древесины. Кроме того, развитие предпринимательства в лесном хозяйстве, в т. ч. малого, является наиболее проблемным в современных условиях хозяйствования. В силу специфики сферы деятельности и отсутствия финансовых возможностей малое предпринимательство в этом секторе экономики демонстрирует недостаточную эффективность в своем развитии, что выражается в увеличении недоимок в бюджеты всех уровней, увеличении масштабов теневой деятельности и др. Результаты опроса руководителей малых предприятий позволили установить, что предприятия могут уводить часть деятельности в тень, в первую очередь, преследуя цель сокращения затрат. По оценкам Всемирного фонда дикой природы, масштабы рубок леса в теневом секторе в России составляет свыше $30 \%$, а в лесоизбыточных регионах до 59-70\%. По экспертным оценкам, федеральный и региональные бюджеты недополучают каждый год в этой связи от 1 до 1,5 млрд руб. лесных платежей. Причинами, способствующими деформации деятельности в малом предпринимательстве, являются неадекватная государственная, правовая и экономическая политика и отсутствие действенных мер по поддержке малого предпринимательства. Это обусловливает необходимость более внимательного исследования реализуемого инструментария государственной поддержки деятельности малого предпринимательства в лесном секторе экономики с учетом существующих в настоящее время факторов деформации бизнеса.

Ключевые слова: малое предпринимательство, лесной сектор экономики, экономическая безопасность, социально-экономическое развитие, экономические показатели, государственное регулирование, предприятия

\title{
Organizational and economic features of the functioning of small enterprises of the forest sector of economics and the causes of strengthening the deformation of enterprise activity
}

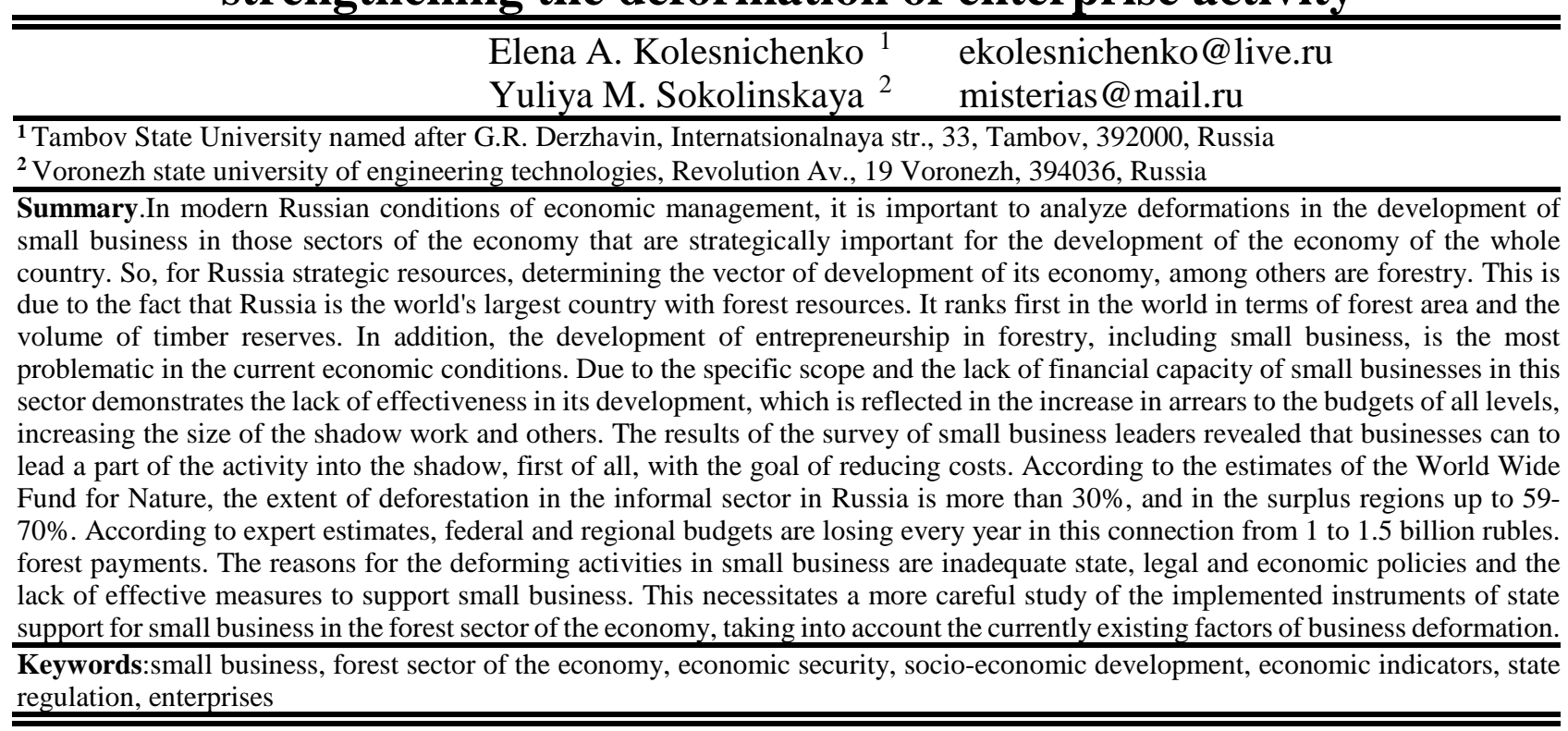

Для цитирования

Колесниченко Е.А., Соколинская Ю.М. Организационноэкономические особенности функционирования малых предприятий лесного сектора экономики и причины усиления деформации предпринимательской деятельности // Вестник ВГУИТ. 2018. Т. 80. № 2. С. 490-496. doi:10.20914/2310-1202-2018-2-490-496 490
For citation

Kolesnichenko E.A., Ju.M. Sokolinskaya Organizational and economic features of the functioning of small enterprises of the forest sector of economics and the causes of strengthening the deformation of enterprise activity. Vestnik VGUIT [Proceedings of VSUET]. 2018. vol. 80. no. 2. pp. 490-496. (in Russian). doi:10.20914/2310-1202-2018-2-490-496 


\section{Введение}

Проведенный кластерный анализ показал, что наибольшее внимание по проблеме поддержки малого предпринимательства в лесном секторе экономики и усиление работы по минимизации уровня деформации предпринимательской деятельности должно уделяться в регионах, относимых к кластеру Низкая доходность государства - Высокий уровень деформации предпринимательской деятельности. Для решения проблемы разработки соответствующего инструментария поставлена задача - выявить причины усиления деформации малого предпринимательства. В качестве гипотезы представлены следующие причины:

Во-первых, множество субъектов экономических отношений в лесном секторе, с разнонаправленными интересами. Нами были определены виды конфликтов интересов хозяйствующих субъектов в системе усиления деформации малого предпринимательства лесного сектора экономики:

- государство - получатель платежей за пользование лесными ресурсами;

- предпринимательские структуры производители и потребители лесной продукции;

- общество (граждане), потребляющее общественные и частные блага;

- выполнение лесными ресурсами экономической функции и экологической (рекреационной).

\section{Основная часть}

Обратимся к более подробному рассмотрению выше представленных противоречий. Таким образом, нами выделены следующие противоречия в системе деформации малого предпринимательства лесного сектора:

1. Противоречия между выполнением лесными ресурсами экономических и экологических (рекреационных) функций. Конфликт между экономическими и экологическими (рекреационными) функциями лесных ресурсов выступает как частое проявление общей системы противоречий экономических интересов. Разрешение данного противоречия имеет страновые особенности. К примеру, в зарубежных странах имеющийся экономический эффект не может выступать приоритетным приоритетным по сравнению с возможными потерями в сфере экологии (рекреации). В противовес, в России получение незначительного экономического эффекта для субъекта предпринимательства ставит на второй план значение лесных ресурсов для здоровья и эстетического восприятия человека. Для того, чтобы не брать на себя обязательства по восстановлению лесных ресурсов множество предпринимателей осуществляют незаконные рубки.
2. Рассогласованность интересов по поводу количества, качества, способов производства, потребления и цены производимых лесных ресурсов. Данное противоречие возникает между предпринимательским сектором и государственными органами контроля. Дело в том, что лесные ресурсы являются одним из источников не только получения прибыли, но и пополнения бюджета. В условиях кризиса данное противоречие усиливается. Неучтенный объем лесных ресурсов, подверженных незаконным рубкам не позволяет государственным органам адекватно оценивать масштабы имеющихся ресурсов и планировать их дальнейшее освоение.

3. Противоречия между необходимым и фактическим воспроизводством лесных ресурсов. Наличие данного противоречия связано, в первую очередь, с недостаточностью финансовых ресурсов для осуществления достаточного объема восстановления лесных ресурсов. Во-вторых, несовершенство методов оценки незаконных рубок (рассмотренное нами в предыдущем параграфе) не позволяет адекватно оценит необходимый объем семян и саженцев для лесовосстановления.

4. Структурная рассогласованность между уровнями бюджетной системы РФ по поводу объемов и структуры поступлений. Данная проблема исследуется в сфере региональной экономики и межбюджетных отношений, поскольку переработка лесных ресурсов приносит доход (в воде налога на прибыль) в бюджет федерального уровня, а проблемы экологического и рекреационного характера решаются на региональном уровне.

5. Рассогласованность интересов государства и предпринимательского сектора по поводу налоговых и иных платежей в бюджет. Данная проблема имеет достаточно глубокие корни и рассматривается в системе корректировки налогообложения. Государство через законодательство и фискальные органы пытается частично переложить на малый бизнес недобор налоговых поступлений с крупного предпринимательства и устанавливает непомерно высокие налоги для наполнения бюджета. Чрезмерно жесткая налоговая политика государства неизбежно приводит к замиранию предпринимательской деятельности и к ее перемещению в тень. В любом случае увеличение налогового бремени будет способствовать уходу предпринимателей в тень [1].

6. Рассогласованность интересов государства в случае ситуации максимизации поступлений в бюджет от использования лесных ресурсов и необходимостью их сохранения, а также рационального использования с целью получения экономической прибыли и социального 


\section{Вестник BTYSTTI/Proceedings of VSUET, TII. 80, № 2, 2018}

эффекта в будущем. Данная проблема характерна не только для лесного сектора, но и для добывающих сфер национальной экономики. Противоречие заключается в том, что максимизация доходов характерна для незаконной деятельности, а сохранение экологических ресурсов решается только органами государственной власти.

7. Противоречия между хозяйствующими субъектами в рамках конкурентной борьбы. Решение данного противоречия в пользу теневой деятельности позволяет малым предпринимателям быть конкурентными по сравнению с другим бизнесом, поскольку незаконные вырубки предполагают минимизацию расходов за счет ухода от налогов и иных обязательных платежей.

8. Рассогласованность интересов государства и хозяйствующих субъектов по поводу максимизации прибыли для предпринимательской структуры и необходимостью сохранения лесных ресурсов на будущее.

Раскрытое выше содержание рассогласованности интересов хозяйствующих субъектов подчеркивает неоднозначность и сложность экономических отношений в лесном секторе, приводящие к усилению деформации предпринимательской деятельности, в процессе которой субъекты хозяйствования в различных ситуациях (определяемых их целями) могут реализовывать свои интересы с различных позиций (в том числе и противоречащих сам себе). К примеру, если мы обратимся к исследованию отношений государства и хозяйствующих субъектов, которые выступают в виде пользователей лесных, то выявим, что государство в представленной совокупности отношений может выступать и субъектом, деятельность которого направлена на обеспечение экономической устойчивости предпринимательских структур путем гарантирования защиты от незаконных действий третьих лиц и т. п., и детерминантом возникновения угроз экономической устойчивости, поскольку устанавливает для предпринимательских структур совокупность административных барьеров, нерациональных налогов, а также санкций за нарушение законодательства. Таким образом, противоречия интересов - конфликты, выступающие традиционными для сферы экономики и управления. Но следует отметить, что в лесной сфере деятельности данные противоречия наиболее ярко представлены и оказывают определяющее значение на появление и усиление деформации предпринимательской деятельности за счет усиления ее теневизации.

На основе проведенного анализа деятельности субъектов хозяйствования в лесной сфере, политики, реализуемой государством, а также совокупности причинно-следственных связей между явлениями и процессами, возникающими в лесном секторе экономики, определены:

1. субъекты и объекты экономических отношений, взаимодействие которых детерминирует усиление теневой деятельности малого предпринимательства в лесном секторе экономики;

2. источники возникновения причин усиления деформации малого предпринимательства в лесном секторе экономики;

3. виды получаемого деструктивного эффекта от усиления деформации малого предпринимательства в лесном секторе экономики.

Так причинами усиления деформации малого предпринимательства в лесном секторе экономики выступают противоречия в реализации интересов субъектов хозяйствования в лесном комплексе. В соответствии с данным критерием причины целесообразно разделить на группы:

1. Причины, возникающие при конфликте интересов общества как потребителя общественных благ (снижение показателей, характеризующих экологическую обстановку, повышение показателей, характеризующих преступность в лесном секторе, увеличение лесных пожаров и т. д.).

2. Причины, возникающие при конфликте интересов общества как потребителя частных благ (увеличение дефицита конкретного вида продукта, снижение его качества или повышение цены).

3. Причины, возникающие при конфликте интересов государства как производителя общественных благ в сфере экологии, правопорядка. Криминогенность лесного сектора связана с коррупционной составляющей в деятельности природоохранных организаций, незаконной рубкой, ухода от уплаты налогов, незаконной торговлей древесиной и лесной продукцией. Лоббирование интересов теневого лесного предпринимательства находится в противоречии интересами общества и государственных органов. На масштабы и качество вырубаемых насаждений в большой степени влияет изменение конъюнктура мирового лесного рынка.

4. Причины, возникающие при конфликте интересов государства как получателя платежей в бюджет. В составе данных причин необходимо определить масштабы убыточности бюджета от деятельности лесного комплекса России (рисунок 1).

5. Среди причин усиления деформации малого предпринимательства в лесном секторе экономики можно выделить недостаточную (по мнению международных экспертов) ставку арендной платы за пользование лесом. 


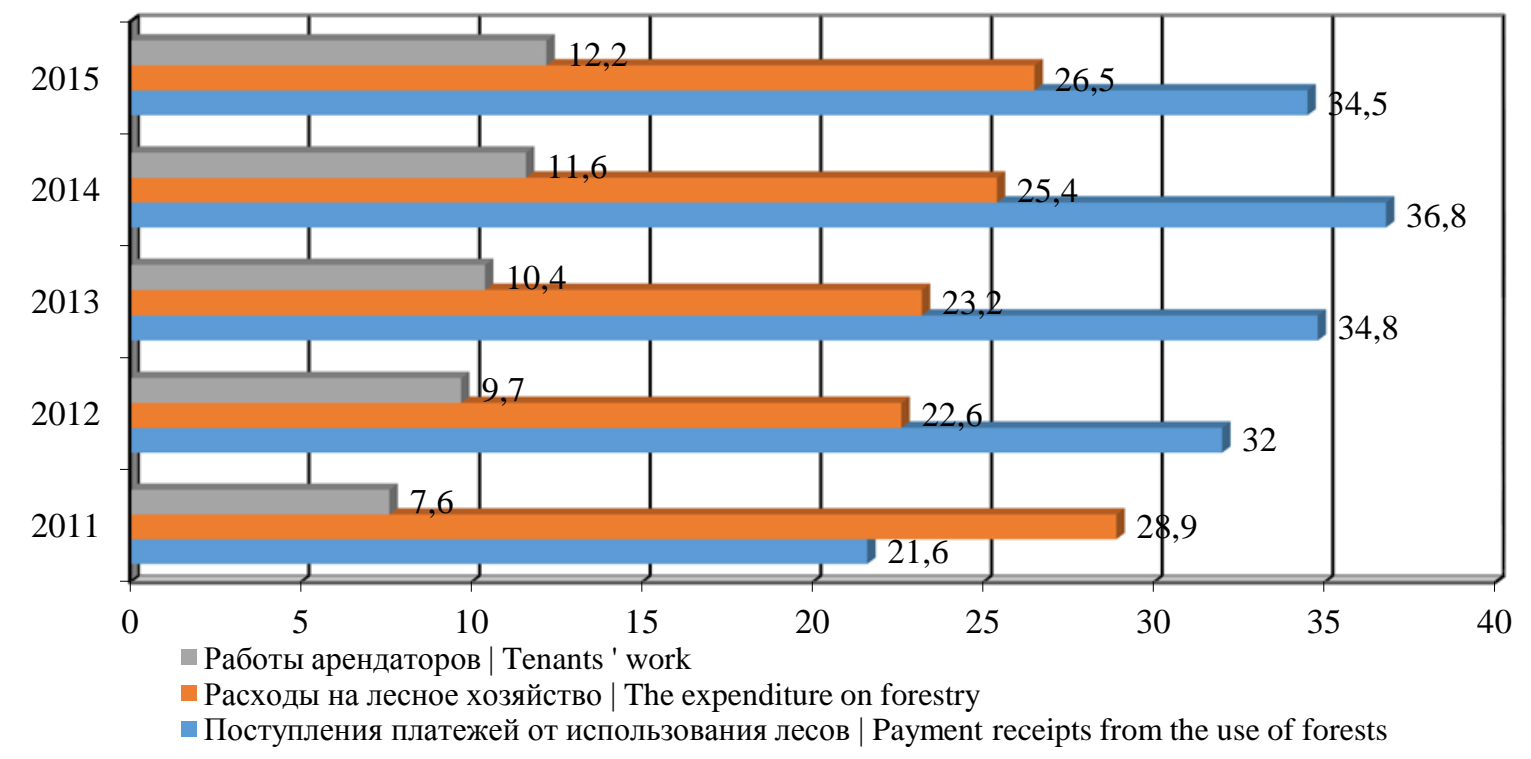

Рисунок 1. Динамика доходов и расходов в системе лесопользования России

Figure1. Dynamics of income and expenditure in the system of forest management in Russia

6. Причины усиления деформации малого предпринимательства в лесном секторе экономики, возникающие при конфликте интересов хозяйствующих субъектов, осуществляющих деятельность в лесном секторе (субъектов лесного сектора).

Данную группу причин целесообразно сгруппировать в зависимости от имеющихся параметров, характеризующих хозяйствующих субъектов:

- по виду используемых природных ресурсов: в хозяйственной деятельности могут использоваться лесные ресурсы, объекты животного мира, полезные ископаемые и др.;

- по способу использования природных ресурсов: в хозяйственной деятельности ресурсы могут использоваться как сырье, территория функционирования, для прочих целей;

- по характеру и виду хозяйственной деятельности: лесозаготовка, обработка древесины и производство изделий из дерева, кроме мебели, производство в лесохимической промышленности, производство целлюлозы, древесной массы, бумаги, картона и изделий из них, производство мебели.

7. Причины усиления деформации малого предпринимательства в лесном секторе экономики, возникающие при конфликте интересов субъектов хозяйствования: контрагенты субъектов лесного комплекса, выступающие в качестве собственников, инвесторы, поставщики и подрядчики, покупатели и заказчики, кредиторы и др.
В зависимости от источника возникновения причин усиления деформации малого предпринимательства в лесном секторе экономики их можно разделить на:

1. Причины усиления деформации малого предпринимательства в лесном секторе экономики, вызываемые государством, выраженные:

- в неэффективности действующего законодательства (в данном случае источник причин находится в нормативном акте, регламентирующем отношения в лесном комплексе). Выполнение требований нормативного акта приводит к ухудшению экономической ситуации в лесном комплексе.

- в неэффективности контроля за исполнением норм хозяйствующими субъектами (в данном случае источник причин находится не в нормативном акте, регламентирующем отношения в лесном комплексе, в сфере его выполнения). Ее наступление или ненаступление зависит от того, насколько эффективно выполняются требования нормативных актов. Кроме того из факторов неэффективного контроля со стороны государственной власти наиболее важной причиной усиления деформации малого предпринимательства в лесном секторе экономики является коррумпированность государственного аппарата. Самыми проблемными для предпринимателей являются представители налоговой инспекции (53\%), общественные организации по защите прав потребителей (55\%). Основная доля предпринимателей отметила в качестве ключевого условия деформации предпринимательской деятельности необходимость неформальных платежей во время проверок. 
Данные исследования показывают, что предприниматели находятся под грузом постоянных проверок со стороны различных контрольных органов.

2. Причины усиления деформации малого предпринимательства в лесном секторе экономики, вызываемые негосударственными природоохранными организациями, связанные:

- с вмешательством в нормотворческую деятельность государственных органов;

- с причинением материального ущерба хозяйствующим субъектам;

- с блокированием деятельности хозяйствующих субъектов.

Наиболее часто упоминаемыми и влиятельными из них являются: Общероссийское движение, BirdLifeInt (международное сообщество охраны птиц), Всемирные союз охраны природы и фонд дикой природы, Гринпис, WNO (международная организация по охране природы), различные союзы (социально-экологический) и службы (экологического аудита и реставрации) и т. д.

Однако, практика лесопользования показывает, что функционирование данных организаций чаще применяется в качестве инструмента обеспечения конкурентоспособности природопользователей, по сути, данные организации преследуют экономически выгодные цели и интересы лоббирующего хозяйствующего субъекта, а задача сохранения окружающей среды становятся второстепенной.

3. Причины усиления деформации малого предпринимательства в лесном секторе экономики, вызываемые хозяйствующими субъектами лесного сектора, связанные: ности;

- с низкой эффективностью их деятель-

- с нарушением законодательства и неисполнением обязательств перед государством (налоговых, природоохранных, иных). Так, по оценкам Всемирного фонда дикой природы, масштабы рубок леса в теневом секторе в России составляет свыше 30\%, а в лесоизбыточных регионах (например, в Красноярском крае) до 59-70\%. По экспертным оценкам, федеральный и региональные бюджеты недополучают каждый год в этой связи от 1 до 1,5 млрд руб. лесных платежей;

- нарушением законодательства и неисполнением обязательств перед контрагентами;

- оказанием негативного воздействия на окружающую среду.

4. Причины усиления деформации малого предпринимательства в лесном секторе экономики, вызываемые 3-ми лицами, связанные:

- с негативным воздействием на окружающую среду;

- с причинением материального ущерба субъектам лесного сектора.
5. Причины усиления деформации малого предпринимательства в лесном секторе экономики, вызываемые объектами природного мира, связанные:

- с сокращением запасов лесных ресурсов;

- с ухудшением климатических условий;

- с ухудшением экологических условий.

Данные виды причин приводят к определенным деструктивным эффектам:

1. Эффект сокращения:

- ресурсов общества, государства, хозяйствующих субъектов (природных, финансовых, материальных, трудовых и пр.);

- деловой активности (производимой продукции) в легальном секторе экономики;

- продукции лесного сектора, в виде частных и общественных благ.

2. Эффект увеличения:

- издержек на хозяйственную деятельность в лесном секторе;

- издержек на приобретение продукции, производимой в лесном секторе;

- рисков для жизни и здоровья;

- деловой активности (производимой продукции) в теневом секторе экономики.

Виды деструктивного эффекта, чаще всего взаимосвязаны между собой. Так, сокращение природных ресурсов лесного сектора может привести к их дефициту, что выразится в более высокой цене доступа к ним. Высокая цена доступа может быть явной (установление государством более высоких ставок за право пользования ресурсами лесного сектора) и косвенной (труднодоступность лесных ресурсов, их удаленность и т. п.). Это, в свою очередь, отразится на снижении деловой активности хозяйствующих субъектов, на дефиците продукции предприятий лесного сектора, а в конечном итоге и на сокращении налоговых доходов государства. Другим отрицательным эффектом роста цены доступа к лесным ресурсам за счет увеличения государством ставок может выступать уход хозяйствующих субъектов в тень. В результате хозяйствующие субъекты смогут удовлетворить свои частные интересы в ущерб интересам государства, однако результативность такого шага для хозяйствующих субъектов будет зависеть от эффективности правоохранительной системы государства.

Однако сами по себе конфликты интересов объектов системы обеспечения экономической устойчивости лесного сектора не являются детерминантами теневой деятельности в лесном секторе экономики. Преобразование их в статус детерминантов происходит при возникновении второго условия: недостаточная эффективность выполнения государством собственных функций по согласованию экономических интересов в лесном секторе экономики. 
Как показывает анализ, существуют системные проблемы рассматриваемой сфере. К ним, в частности, следует относить [2]:

1. Снижение объемов и запасов древесины на территориях, где расположены действующие лесопромышленные предприятия и транспортные пути.

2. Несовершенство применяемых методов и инструментов учета лесных ресурсов.

3. Недостаточная эффективность контроля за использованием лесных ресурсов, осуществляемого государственными органами в регионах.

4. Увеличение масштабов потерь лесных ресурсов от пожаров, вредителей и болезней. Увеличение экономического и экологического ущерба от лесных пожаров, вредных организмов и других факторов по сравнению с общими расходами на охрану, защиту и воспроизводство лесов.

5. Недостаточно высокое качество лесовосстановления.

6. Недостаточный уровень технического оснащения лесохозяйственных работ.

7. Недостаточная инфраструктура в лесном секторе экономики.

8. Постоянно повышающийся уровень теневой деятельности, связанной с оборотом древесины.

9. Снижение разнообразия биологических видов в лесах.

Каждый из названных факторов приводит к возрастанию масштабов деформации малого предпринимательства в лесной сфере экономики [3-6].

В-третьих, нехватка финансовых ресурсов.

Изучение результатов опросов малых предприятий позволяет сделать вывод, что предприниматели практически всегда на первое место выделяют проблему нехватки финансовых ресурсов. Результаты опроса руководителей малых предприятий позволили установить, что предприятия могут уводить часть деятельности в тень, в первую очередь, преследуя цель сокращения затрат. Предпринимательские структуры, осуществляющие свою деятельность без теневой

\section{ЛИТЕРАТУРА}

1 Лысенкова Е.Н. Государственное правовое регулирование малого предпринимательства в целях обеспечения экономической безопасности Российской Федерации. М., 2006. 196 с.

2 Стратегия развития лесного комплекса Российской Федерации на период до 2020 года. URL: http://nacles.ru/

3 Jonsson R. et al. What is the current state of forest product markets and how will they develop in the future? // European Forest Institute. 2017. V. 2017. P. 126-131.

4 Nabuurs G. J. et al. A new role for forests and the forest sector in the EU post-2020 climate targets // European Forest Institute. 2015. №. 2. составляющей, получают более высокие затраты, чем предпринимательские структуры, работающие в тени. В этой связи усиление теневой деятельности выступает способом поддержания конкурентоспособности и необходимостью выживать на рынке [7-10].

Таким образом, причиной перехода предпринимателей в теневой сектор при нехватке финансовых средств выступают:

- превышение доходности незаконных рубок над законными;

- недостаточная занятость трудовых ресурсов в лесных регионах России;

- сравнительно низкий уровень доходов населения в лесных регионах России.

Кроме того, не менее важным фактором, обуславливающим уход малого предпринимательства в тень, является высокая налоговая нагрузка (это отметили $38 \%$ опрошенных предпринимателей). Нерациональное налогообложение, сравнительно высокие ставки налогообложения выступают ключевой причиной перехода в тень предпринимателей в лесном секторе и сокрытия реальных масштабов их деятельности.

Несмотря на то, что малому и среднему предпринимательству со стороны государства оказывается различная организационная и финансовая поддержка, число субъектов малого предпринимательства работающих в тени, как и число предприятий банкротов остается стабильно высоким.

\section{Заключение}

Теневая экономика и кризисы имеют место при наличии низких показателей социальноэкономического развития, несовершенного законодательства, высокого уровня налогообложения, в сочетании с неэффективной поддержкой малого предпринимательства. На основании вышесказанного сделаем вывод, что причинами, способствующими деформации деятельности в малом предпринимательстве, являются неадекватная государственная, правовая и экономическая политика и отсутствие действенных мер по поддержке малого предпринимательства.

5 Näyhä A., Pelli P., Hetemäki L. Services in the forest-based sector-unexplored futures // Foresight. 2015. V. 17. №. 4. P. 378-398.

6 Overdevest C., Zeitlin J. Assembling an experimentalist regime: Transnational governance interactions in the forest sector // Regulation \& governance. 2014. V. 8. №. 1. P. 22-48.

7 Roos A., Stendahl M. The emerging bioeconomy and the forest sector // Forests, Business and Sustainability. 2015. P. 179.

8 Кандакова Г.В. Проблемы повышения конкурентоспособности аграрного сектора россии в условиях вступления в вто и направления их решения // Вестник Воронежского государственного университета инженерных технологий. 2013. №4. С. 307-311. 
9 Широ М.С. Приоритетные направления формирования инновационной инфраструктуры регионов Южного Федерального округа // Вестник Воронежского государственного университета инженерных технологий. 2016. №2. С. 249-256.

\section{REFERENCES}

1 Lysenkova E.N. Gosudarstvennoe pravovoe regulirovanie malogo predprinimatelstva $v$ tseliakh obespecheniia ekonomicheskoi bezopasnosti Rossiiskoi Federatsii [State legal regulation of small business in order to ensure economic security of the Russian Federation] Moscow, 2006. 196 p. (in Russian)

2 Strategiia razvitiia lesnogo kompleksa Rossiiskoi Federatsii na period do 2020 goda [Strategy of development of the forestry complex of the Russian Federation for the period until 2020] Available at: http://nacles.ru (in Russian)

3 Jonsson R. et al. What is the current state of forest product markets and how will they develop in the future? European Forest Institute. 2017. vol. 2017. pp. 126-131.

4 Nabuurs G. J. et al. A new role for forests and the forest sector in the EU post-2020 climate targets. European Forest Institute. 2015. no. 2.

\section{СВЕДЕНИЯ ОБ АВТОРАХ}

Елена А. Колесниченко д.э.н., профессор, кафедра кадрового управления, Тамбовский государственный университет имени Г.Р. Державина, ул. Интернациональная, 33, Тамбов, 392000, Россия, ekolesnichenko@live.ru

Юлия М. Соколинская ст. преподаватель, кафедра экономической безопасности и финансового мониторинга, Воронежский государственный университет инженерных технологий, пр-т Революции, 19, г. Воронеж, 394036, Россия, misterias@mail.ru

\section{КРИТЕРИЙ АВТОРСТВА}

Елена А. Колесниченко консультация в ходе исследования Юлия М. Соколинская написала рукопись, корректировала её до подачи в редакцию и несёт ответственность за плагиат

КОНФЛИКТ ИНТЕРЕСОВ

Авторы заявляют об отсутствии конфликта интересов.

ПОСТУПИЛА 12.04.2018

ПРИНЯТА В ПЕЧАТЬ 16.05.2018
5 Näyhä A., Pelli P., Hetemäki L. Services in the forest-based sector-unexplored futures. Foresight. 2015. vol. 17. no. 4. pp. 378-398.

6 Overdevest C., Zeitlin J. Assembling an experimentalist regime: Transnational governance interactions in the forest sector. Regulation \& governance. 2014. vol. 8. no. 1. pp. 22-48.

7 Roos A., Stendahl M. The emerging bioeconomy and the forest sector. Forests, Business and Sustainability. 2015. pp. 179.

8 Kandakova G.V. Problems of improving the competitiveness of the russian agricultural sector in wto accession and their solutions ways. Vestnik VGUIT [Proceedings of the Voronezh State University of Engineering Technologies] 2013. no. 4. pp. 307-311. (in Russian)

9 Shiro M.S. Priority areas for the formation of innovation infrastructure of the Southern Federal District. Vestnik VGUIT [Proceedings of the Voronezh State University of Engineering Technologies] 2016. no. 2. pp. 249-256. (in Russian)

\section{INFORMATION ABOUT AUTHORS}

Elena A. Kolesnichenko Cand. Sci. (Engin.), associate professor, Personnel Management department, Tambov State University named after GR. Derzhavin department, Internatsionalnaya str., 33, Tambov, 392000, Russia, ekolesnichenko@live.ru

Yuliya M. Sokolinskaya Senior Lecturer, Economic Security and Financial Monitoring department, Voronezh state university of engineering technologies, Revolution Av., 19 Voronezh, 394036, Russia,misterias@mail.ru

\section{CONTRIBUTION}

Elena A. Kolesnichenko consultation during the study Yuliya M. Sokolinskaya wrote the manuscript, correct it before filing in editing and is responsible for plagiarism

CONFLICT OF INTEREST

The authors declare no conflict of interest.

RECEIVED 4.12.2018

ACCEPTED 5.16.2018 